\title{
Setting up comprehensive and Researching Experiments to Reform Organic Chemistry Experiment Teaching Method
}

\author{
Ting Liu, Xu LI \\ Department of Biology and Chemistry \\ Nanchang University college of Science and Technology \\ Nanchang, China \\ E-mail: patrickheroin@sohu.com
}

\begin{abstract}
Organic synthesis experiment is a obligatory course of senior students major in chemistry and it is also an important practical teaching link to prepare for the graduation thesis. The course aims to broaden the students' knowledge, cultivate the students' innovation consciousness, enhance their abilities to find out the problems, analyze and solve the problems, and independently think through the experiments of comprehensive practice. The necessity of teaching reform, the significance of carrying out investigative practice teaching and research practice teaching reform were discussed in this paper respectively.
\end{abstract}

Keywords- Organic synthesis experiment; reform on practice teaching; Research learning

\section{INTRODUCTION}

With the rapid development of the increasing progress of the society and economy, the requirements on the talents are also risen to a new level. In the era of knowledge update fast, the development of economy and society needs more technological talents with innovative consciousness and pioneering spirit, and a complete education system is the only channel to provide such reserve talents. To cultivate students' innovation spirit and practice ability, greatly exert students' subjective initiative, we must effectively change the traditional exam-oriented teaching way, advocate a kind of effective education system more suitable for cultivating the students. Under the background of educational reform, it is a historical necessity to apply inquiry learning into the chemistry education teaching process in university.

\section{THE IMPORTANT SIGNIFICANCE OF SETTING UP ORGANIC COMPREHENSIVE SYNTHESIS EXPERIMENT}

University chemistry experiment consists of basic chemical experiment and comprehensive chemistry experiment. Comprehensive experiment in organic synthesis is mainly to expand the training of the students' comprehensive ability; its experiment content should reflect the subject development trend. It is also a practical course to strengthen students' chemical synthesis skills.

The chemical experimental ability which is an integrated ability combined by many compositions can not simply equal to the experimental operating skills. It is an approach combined with the basic chemistry knowledge and experimental skills. It is an effective way to cultivate student s abilities of analysis and summary. On the basis of the study, when question-situation is created in chemistry teaching, creating question-situation and optimizing experimental teaching permeate through one another. As the concentration practice, this course is an important way to cultivate students' innovative consciousness and practice ability. To deepen the students' professional knowledge, train the students' practice ability and improve the students' ability to analyze and solve the problems independently, and comprehensively promote quality education, this course has a special important significance.

In addition, this course has a comprehensive experimental skills, independence of the experiment operation, and other characteristics. In the practice teaching, students are required to consult literature materials, design experiment course, independently solve problems encountered in the experiment, change the previous experiment completely depending on the teachers' passive situation, fully arouse the enthusiasm of the students, dig the potentials of the students.

And it is conducive to broaden the students' knowledge, make students understand and learn new knowledge in the field of academic frontiers and advanced modern technology experiment, improve the students' interests and cultivate the ir innovative ability of scientific research. It is good for students to put what they have learned the knowledge combined with production practice, let the student have the feeling of "knowledge", improve the students' interests in learning, and cultivate the students' creative abilities.

\section{THE NECESSITY OF COMPREHENSIVE EXPERIMENT TEACHING REFORM IN ORGANIC SYNTHESIS}

Conducting research practice teaching is the fundamental requirement of cultivating innovative talents. How to give full play to the role of the practice teaching and how to cultivate innovative talents have become the important problems of all kinds of practice teaching that we must consider. The cultivation of innovative talents depends on not only the classroom imparting theoretical knowledge, also with the aid of practice teaching and the needs to strengthen the practice teaching. Therefore, the practice 
teaching effect is good or bad has an important influence for the cultivation of innovative talents ${ }^{[1]}$.

General practice teachings at vast majority universities are still stay on the level of "knowledge verification", the practice of the traditional teaching mode is not conducive to the students' knowledge innovation, unfavorable to the cultivation of innovative talents, and the reform of the practical teaching method must be carried out. Organic synthesis experiment curriculum's aim is to promote the students' knowledge, ability, thinking and quality of comprehensive coordinated development on the basis of making the students completing organic chemistry experiment through the implementation of open teaching.

In the traditional experiment teaching, apparatus, chemicals or instruments for the laboratory experiment are all readied by teacher, and the teacher will give detailed explanation and demonstration before the experiment started, students only need to repeat each step in accordance with the samples, the exam-oriented education completely can not stimulate the students' interests, exert students' subjective initiative and innovative ability.

Experimental teaching reform has the guiding ideology that chemistry experiment is not only to teach chemistry knowledge, validation, and chemical theory, master the basic operation skills, but also should pay more attention to the cultivation of ability and quality, raises student's beginning ability, innovation consciousness and scientific thinking through the experiment.

In order to realize the change of the experimental teaching idea, break the old experimental system, build a new experiment system, fundamentally change the idea that comprehensive experiment in organic synthesis experiment teaching completely attached to the traditional concept of theory teaching,

The reform in organic synthesis of comprehensive experiment teaching methods has been carried on, and the key is to reform experiment course system, teaching content, teaching mode, teaching method and means, teaching management and so on.

\section{APPLY RIGHT TEACHING WAYS, AROUSE THE CURIOSITY OF THE STUDENTS}

In the process of experiment teaching, teacher should first clear the important role of chemistry in the 21st century, including chemical and social relations, important influence on the social development. Chemical discipline is positively penetrating into other subjects, and has a significant influence on science and technology, life field. In fact, let the students understand the relationship between chemistry and society is an important part of quality education in the experimental teaching. Let students understand the emerging frontier disciplines can help students to broaden their horizons.

Comprehensive experiment teaching use inquiry teaching methods in organic synthesis. The basic skills such as heating, cooling, drying, mixing, filtering, atmospheric distillation, vacuum distillation, extraction and column chromatography separation operations will be taught through visual presentation, video, animation, and other forms, it will not only increase the authority of the teaching and normative, but also make the simple, boring story become more vivid, and deepen the impression of the student, inspire the students' interests in learning, lay a good foundation for subsequent experiments ${ }^{[2]}$.

In traditional teaching mode, teaching is the main body; students have no independent innovation consciousness and subjective initiative. Teachers should be in line with the service of teaching and students, highlight student's main body status, and guide students to actively participate in teaching environment, stimulate students' learning enthusiasm, training the students' subjective initiative. Investigative practice teaching will introduce the "inquiry learning" into the experimental class, implementing the correct teaching methods.

The way to finish the experiment is accordance with logical thinking including raising questions, analyzing and solving the problems. Students under the guidance of teachers, through browsing the literature to obtain relevant information with the experiment, and design a reasonable experiment method, form a study report, and discuss with each other. Compared with the traditional exam-oriented education, this kind of study way is more attractive, and it can mobilize students' subjective initiative more effectively.

Before experiment, providing students with the method to browse literature, let themselves to design experimental steps, understand the mechanism and experimental principle involved in each step reactions, learn how to use the apparatus ,drugs and solvent needed in each step, and then write them down in the book of the prereview report.

Full preparation can help students know the detailed process of the experiment. In the process of accessing to information, recording and preparing reports, students' ability of independent thinking and the ability to solve specific problems can be cultivated.

In the Experimental lessons, providing students with hands-on opportunities as more as possible, can raise student's ability to work independently. After the experiment, students are required to arrange the experimental results, write a detailed experiment report. Except the basic compulsory experiment, teacher can cooperate with the students' interest to arrange another different choise for them, to mobilize the enthusiasm and initiative of students. The preview with independent thinking to conduct actual operation, deal with the results of objective, cultivate the students "inquiry learning" mode, effectively plays the subjective initiative of students.

"Inquiry learning" is a practical learning, which is full of fun and challenging. Students must do it by themselves, and to realize the "how to do". Through the extended study, the student's skills and abilities will be increased to the largest degree, and their innovation spirit and ability of self 
education will be developed too. Operating "inquiry learning" in organic synthesis experiment can cultivate students' practical ability, pioneering ability and their ability of collecting and processing information science, the ability of acquiring new knowledge, analysis and problem solving skills, as well as the communication and cooperation ability and so on.

V. REFORMING EXPERIMENT CONTENT AND EXAMINATION MODE, AND IMPROVING THE INNOVATION ABILITY

Comprehensive experiment in organic synthesis as a centralized practice in the training plan is a test for students' comprehensive knowledge use skill. In the inorganic chemistry experiment, analytical chemistry experiment, normal chemistry experiment and organic chemistry experiment courses, the students have a certain basic experiment skills and professional knowledge, their observation ability, understanding ability and practice ability have improved to a certain degree.

Under the premise, comprehensive experiment in organic synthesis was set up. It is different from some recognition of the production practice, also has the very big difference with general experiment course. It mainly contains research, comprehensive and designing experiments. The practice of learning can help students to further consolidate the existing knowledge and the self learning, self education can widen our sight and deeper link between theory and practice. The preview report grade accounts for $50 \%$, this part mainly includes the experimental route design being reasonable or not, experiment steps being correct or not, the experimental principle being clear or not, whether detail the experimental instruments used in the experiment being detail or not, etc., It mainly explores the students' ability of independent thinking, subjective initiative and innovative ability. The experiments result accounts for $30 \%$, this part mainly includes attendance, experimental attitude, practical operation ability and so on and investigates the students' practical ability and the ability to deal with problems independently; The experiment report score accounts for $20 \%$, this part mainly includes the experiment report writing organization, experimental data recording and processing of norms as well as the experiment result being reasonable and credible or not. Cultivating the students' rigorous and realistic scientific attitude can, more effectively play the subjective initiative of students ${ }^{[3]}$.

\section{ACKNOWLEDGMENT}

This subject comes from " the Project on Teaching Team of Basic Chemistry Course " financially supported by Nanchang University College of Science and Technology.

\section{REFERENCES}

[1] CAO Min-hui CHEN Chang-shui XU Sheng-zhen, "Exploration and reform of organic chemistry testing method", Experimental T echnology and Management, vol. 24, pp. 117-119, Feb. 2007.

[2] ZHAO Tong-jian, "Innovation on reform of teaching pattern on organic chemistry experiment”, Journal of Shaanxi Normal U niversity ( Natural Science Edit ion), vol 35, pp. 198-201,Nov. 2007.

[3] ZHANG Yan-li, JIN Chang-lei, LI Ai,etc. "Building the Teaching System in Organic Chemistry Experiments Application-oriented Talents”Training”, RESEARCH AND EXPLORATION IN LABORATORY, vol. 30, pp. 138-140, Feb. 2011. 